\title{
STUDI PERENCANAAN PEMBANGKIT LISTRIK TENAGA PICOHYDRO (PLTPh) RUMAH TANGGA
}

\author{
Sepannur Bandri ${ }^{1)}$, Aswir Premadi ${ }^{2)}$, Rafika Andari ${ }^{3{ }^{*}}$ \\ Fakultas Teknik, Institut Teknologi Padang \\ email: rafika.andari09@gmail.com
}

\begin{abstract}
Abstrak
Abstrak : Perkembangan pembangunan pembangkit listrik terus dilakukan untuk memenuhi kebutuhan kelistrikan masyarakat. Namun, pembangkit yang telah ada masih sangat mahal sehingga diperlukan sebuah pembangkit listrik sederhana yang memiliki biaya dan lahan yang minim. Pembangkit Listrik Tenaga Picohydro (PLTPh) merupakan salah satu alternatif pembangkit listrik yang lebih murah dan tidak membutuhkan lahan yang luas. Secara teknis, picohydro memiliki tiga komponen utama yaitu air (sumber energi), turbin dan generator. Potensi alam yang dapat dijadikan suatu pembangkit picohydro adalah air hujan. Perencanaan picohydro ini menggunakan curah hujan di Kota Padang sebagai sumber energi primer yang dihitung berdasarkan luas permukaan atap rumah, dimana curah hujan rata-rata $24.154 \mathrm{~mm} /$ menit. Air hujan akan ditampung pada tangki berukuran 5100 liter dengan luas pipa pesat 1.2 inci dengan kecepatan air $6.26 \mathrm{~m} / \mathrm{s}$, sehingga debit air yang dimanfaatkan 6.9 liter/s. Turbin yang digunakan adalah turbin reaksi propeller open flume TC 60 dan generator sinkron satu fasa kapasitas dapat melebihi 100 Watt, $200-220$ volt, $90 \mathrm{~Hz}$ dengan head 3 meter. Daya keluaran yang dihasilkan adalah 173.43 watt, dimana untuk turbin propeller memiliki efisiensi 0.85 dan efisiensi generator 0.9. Rencana anggaran biaya yang dibutuhkan untuk pembangunan PLTPh ini adalah sebasar Rp. 12,713,855.
\end{abstract}

Kata kunci: Pembangkit listrik, Picohydro, Turbin reaksi

\begin{abstract}
The development of the construction of power plants continue to be done to meet the needs of the electrical society. However, the plants are still very expensive so it is required a simple power generator that has a cost and minimal land. Picohydro Power Plant (PLTPh) is one of the alternative power plant that is cheap and does not require large tracts of land. Technically, picorohydro has three main components, namely water (source of energy), turbine and generator. Natural potential that can be used as a generator picohydro is rain water. This picohydro plan uses rainfall in Padang City as the primary energy source calculated based on th e surface area of the roof of the house, where the average rainfall is $24,154 \mathrm{~mm} / \mathrm{min}$. Rain water will be accommodated on a tank-sized 5100 liters with the area of the pipe rapidly 1.2 inches with a water speed of $6.26 \mathrm{~m} / \mathrm{s}$, so that the flow of water utilized 6.9 litres $/ \mathrm{s}$. Turbine is a reaction turbine propeller open flume TC 60 and synchronous generator single phase capacity can exceed 100 Watts, $200-220$ volts, $90 \mathrm{~Hz}$ with the head of 3 meters. The output power generated is 173.43 watts, where to turbine propeller turbine efficiency 0.85 and the efficiency of the generator 0.9. Plan and the budget needed for the construction of the Phpp this is sebasar Rp. 12,713,855.
\end{abstract}

Keywords : power plant, picohydro, reaction turbine

\section{PENDAHULUAN}

Energi merupakan suatu kebutuhan yang sangat penting bagi kehidupan manusia. Salah satu energi yang sangat dibutuhkan manusia adalah energi listrik. Banyak aktivitas manusia yang dilakukan dengan memanfaatkan energi listrik baik di lingkungan rumah tangga, industri, transportasi dan lain-lain. Kebutuhan masyarakat akan energi listrik dari waktu ke waktu terus meningkat, seiring dengan berubahnya gaya hidup masyarakat. Perkembangan pembangunan fasilitas kelistrikan terus dilakukan untuk memenuhi kebutuhan kelistrikan masyarakat. Namun pada kenyataannya 
masih banyak daerah-daerah di Indonesia yang masih mengalami pemadaman listrik secara berkala maupun yang belum terjangkau aliran listrik.

Dalam rangka diversifikasi penggunaan energi primer dapat dilakukan dengan cara mengoptimalkan pemanfaatan energi terbarukan. Pemanfaatan energi terbarukan ini juga didasari dengan kelangkaan energi tak terbarukan. Di Indonesia sumber energi terbarukan sangat banyak, seperti energi surya, panas bumi, angin, arus laut, pasang laut, biogas maupun biomassa. Pengoptimalan energi terbarukan khususnya potensi tenaga air atau energi setempat telah banyak digunakan untuk pembangkit listrik. Oleh sebab itu, kini banyak berkembangnya pembangkit listrik sederhana yang memiliki biaya dan lahan yang minim sehingga dapat memenuhi kebutuhan listrik masyarakat serta menjadi energi cadangan untuk kebutuhan.

Pembangunan Pembangkit Listrik Tenaga Air baik dalam sekala besar ataupun kecil dapat membantu penyediaan tenaga listrik yang diamanatkan dalam pasal 4 ayat 3 UU No. 20 Tahun 2002. Tentang Ketenagalistrikan disebutkan "guna menjamin ketersediaan energi primer untuk pembangkit tenaga listrik, diprioritaskan penggunaan sumber energi setempat dengan kewajiban mengutamakan pemanfaatan sumber energi terbarukan".

Selain itu, pemerintah juga telah membuat peraturan perundang-undangan yang akan menunjang investasi dalam bidang Pembangkit Listrik Tenaga Air, antara lain :

1. Peraturan Pemerintah No. 03 tahun 2005 Tentang Ketenagalistrikan, dimana dalam Pasal 2 ayat 3 dan 4 menyatakan :

Ayat 3 : "Penyediaan tenaga listrik dilakukan dengan memanfaatkan seoptimal mungkin sumber energi yang terdapat di wilayah negara kesatuan Republik Indonesia”.
Ayat 4 : "Guna menjamin ketersediaan energi primer untuk penyediaan tenaga listrik untuk kepentingan umum, diprioritaskan penggunaan sumber energi setempat dengan kewajiban mengutamakan pemanfaatan sumber energi terbarukan".

2. Peraturan Menteri Energi Dan Sumber Daya Mineral No. 001 tahun 2006 Tentang Prosedur Pembelian Tenaga Listrik Dan/Atau Sewa Menyewa Jaringan Dalam Usaha Penyediaan Tenaga Listrik Untuk Kepentingan Umum.

3. Peraturan Menteri Energi Dan Sumber Daya Mineral No. 002 tahun 2006 Tentang Pengusahaan Pembangkit Listrik Tenaga Terbarukan Skala Menengah.

Dalam beberapa penelitian telah banyak disinggung mengenai Pembangkit Listrik Tenaga Picohydro (PLTPh). Pada penelitian "Studi Perencanaan Pembangkit Listrik Picohydro (PLTPh) Untuk Produksi Keripik di Daerah Banjarnegara". Hasil penelitian menunjukkan bahwa paling optimal pada head 3-3.5 meter dan debit $361 /$ dtk adalah $45^{\circ}$; untuk debit 29$33 \mathrm{l} / \mathrm{dtk}$ adalah $40^{\circ}$; untuk debit $28 \mathrm{l} / \mathrm{dtk}$ adalah $35^{\circ}$ dan untuk debit 25 1/dtk adalah $30^{\circ}$. Keadaan ini menunjukkan Turbin Open Flume OF. 125 masih dapat digunakan pada musim kemarau dengan debit 25 1/dtk menghasilkan daya 264 watt. Dengan kata lain optimalisasi pemakaian turbin sepanjang waktu dapat digunakan dengan merubah kemiringan sudut sudu roda jalan (runner) apabila debit air berubah (Sugianto, 2012).

Pada penelitian "Perancangan dan pembuatan Pembangkit Listrik Untuk Rumah Tangga di Pedesaan", telah dibuat pembangkit picohydro berdaya 100 watt untuk perumahan di pedesaan dengan tanpa machining, efisiensi maksimun pembangkit $36 \%$ yang terjadi pada sudut sudu turbin $30^{\circ}$ pada debit 6,2 liter/s dengan Head 2 meter serta daya yang 
dihasilkan adalah 96 Watt (Shantika, 2013).

Pada penelitian "Perancangan dan Realisasi Sistem Pengisian Baterai 12 Volt 54 AH Pada Pembangkit Listrik Tenaga Picohydro di UPI Bandung" telah dicoba memanfaatkan listrik tersebut untuk sistem pengisian baterai, dimana dirancang dan direalisasikan suatu alat untuk mengisi baterai dengan tegangan charging 14,2 Volt dan arus pengisian maksimal 4,5 Ampere yang bersumber dari pembangkit pikohidro.

Pada penelitian "Perencanaan Pembangkit Listrik Tenaga Air Skala Pikohidro di Area Wisata Curug Embun Desa Pematang Bange Kota Pagaralam”. Hasil Studi Perencanaan Pembangkit Listrik Pikohidro di area wisata Curug Embun Desa Pematang Bange kota Pagaralam Dengan besar potensi energi potensial pada aliran air dipengaruhi oleh Head, sehingga aliran air dapat mengerakkan baling poros turbin dan generator yang menghasilkan energi listrik

Picohydro adalah jenis pembangkit listrik tenaga air dengan kapasitas kecil, sehingga berimplikasi pada relatif sederhananya peralatan yang digunakan. Keunggulan picohydro yaitu tidak menimbulkan kerusakan lingkungan, Picohydro dirancang menghasilkan daya terbangkit $100 \mathrm{~W}-5 \mathrm{~kW}$ dan memanfaatkan potensi tenaga air dengan head yang rendah sebagai tenaga penggeraknya, (Risnandar dkk, 2011). Air hujan yang yang biasanya kurang dimanfaatkan juga dapat dijadikan sumber pembangkit dengan menampung air hujan pada bak penampungan. Oleh karena itu maka penulis sangat tertarik untuk melakukan penelitian dengan judul : "Studi Perencanaan Pembangkit Listrik Tenaga Picohydro (PLTPh) Rumah Tangga“, dimana penelitian ini akan menerapkan pemanfaatan terhadap air hujan untuk perencanaan tersebut.

\section{METODE PENELITIAN}

Metode yang dilakukan adalah research and development, yaitu suatu proses atau langkah-langkah untuk mengembangkan suatu produk baru atau menyempurnakan produk yang telah ada yang dapat dipertanggungjawabkan. Metode ini memuat 3 komponen utama yaitu : model pengembangan (prosedural, konseptual dan teoritik), prosedur pengembangan penelitian dan uji coba produk.

Adapun langkah-langkah untuk melakukan perencanaan Pembangkit Listrik Tenaga Picohydro (PLTPh) ini seperti disajikan pada gambar berikut :

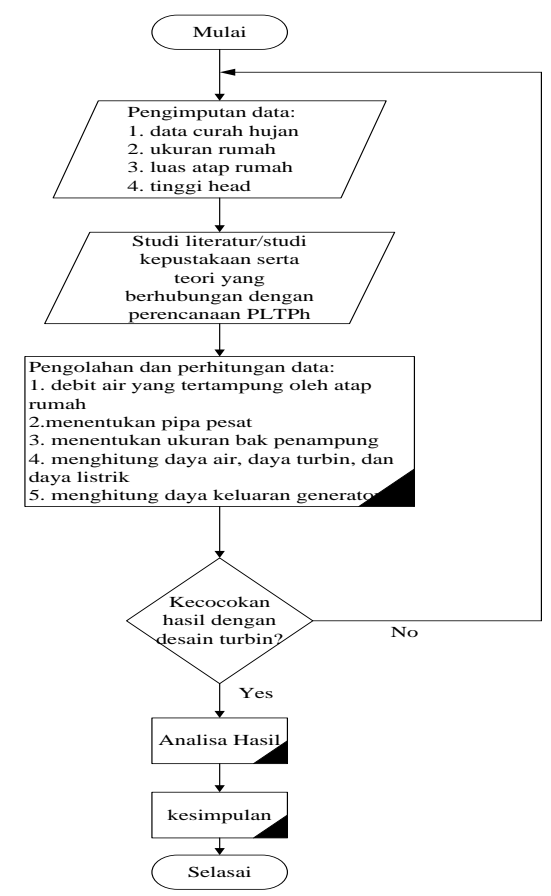

Gambar 1. Kerangka Metodologi

\section{Penginputan Data}

Adapun data yang dibutuhkan dalam penelitian ini, yaitu :

1. Data curah hujan yang diperoleh dari BMKG kota Padang

Data curah hujan yang digunakan yaitu data curah hujan periode JanuariDesember 2016.

2. Pengukuran ukuran rumah/bangunan Untuk menghuting luas atap rumah yang dapat dilihat pada persamaan (1) berikut : 


$$
l=\frac{l_{1}+l_{2}}{\cos \alpha}
$$

Dimana:

Pada bagian lebar atap rumah, lebar rumah dibagi menjadi 2 sisi, yaitu

$l_{1}=$ sisi kiri $(\mathrm{m}$ atau $\mathrm{cm})$

$l_{2}=$ sisi kanan $(\mathrm{m}$ atau $\mathrm{cm})$

Lebar kanan dan kiri dibuat lebih panjang dari lebar bangunan.

$\cos a=$ sudut dari kemiringan atap rumah

Perencanaan bentuk dan ukuran atap bangunan seperti disajikan pada gambar di bawah ini.

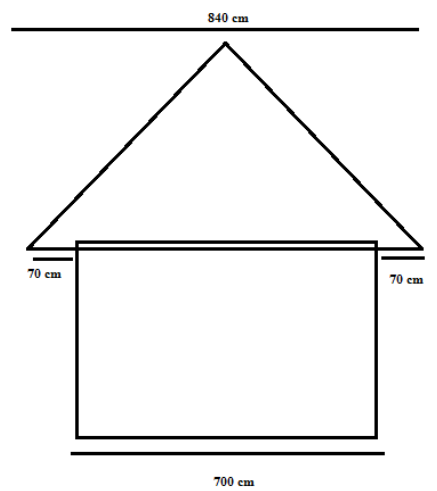

Gambar 2. Ukuran Bangunan PLTPh

3. Pengukuran tinggi air terjun / ketinggian Head $(\mathrm{H})$

Panjang pipa pesat yang digunakan untuk mengalirkan air rumah turbin agar turbin berputar dapat menggunakan rumus phytagoras seperti pada persamaan (2) dan disajikan seperti pada Gambar 3.

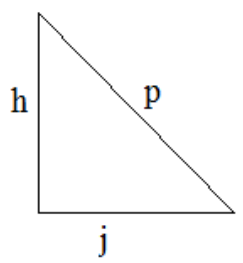

Gambar 3. Segitiga Phytagoras

$$
P=\sqrt{h^{2}+j^{2}}
$$

Dimana :

$\mathrm{P}=$ panjang pipa $(\mathrm{m})$

$\mathrm{h}=$ head $(\mathrm{m})$

$\mathrm{j}=$ jarak dari rumah turbin dari garis vertical head (m)

\section{Pengolahan dan Perhitugan Data}

\section{Debit Air}

Debit air merupakan hal yang sangat menentukan dalam perencanaan turbin air, karena daya yang dihasilkan oleh turbin sangat tergantung pada debit air yang tersedia (Arismunandar, 2000). Menurut persamaan kontinuitas debit air yang mengalir dalam pipa bertekanan dapat ditentukan dengan persamaan (3) :

$$
Q=V \cdot A
$$

Dimana :

$Q=$ Debit air $\left(\mathrm{m}^{3} / \mathrm{s}\right)$

$\mathrm{V}=$ Kecepatan aliran air $\quad(\mathrm{m} / \mathrm{s})$

$\mathrm{A}=$ Luas penampang pipa $\quad\left(\mathrm{m}^{2}\right)$

Dari bentuk di atas dapat dihitung luas penampang sungai dengan cara menjumlahkan luas daerah - daerah yang berbentuk trapesium. Setelah didapatkan kecepatan air di sungai dapat diukur dengan bantuan pengapung yang dihanyutkan pada sungai dan dihitung waktunya ketika menempuh jarak tertentu. Pengukuran itu dilakukan pada tiap - tiap titik yang telah ditentukan seperti yang di atas dan dilakukan untuk beberapa pengukuran dan kemudian kecepatan pada satu titik itu dirata-ratakan kecepatan pada titik titik tersebut.

\section{Perencanaan Pipa Pesat}

Pipa pesat adalah pipa yang dipakai untuk mengalirkan air ke turbin. Pipa silinder digunakan untuk pipa pesat dan pipa dari talang air disajikan seperti pada Gambar 4.

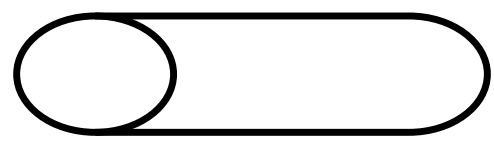

Gambar 4. Bentuk Pipa Pesat

Untuk perhitungan pipa dapat dilakukan menggunakan persamaan (4):

$$
V=\pi r^{2} t
$$

Dimana :

$$
\mathrm{V}=\text { volume talang }\left(\mathrm{m}^{3}\right)
$$




$$
\begin{aligned}
& \pi=3.14 \text { atau } 22 / 7 \\
& \mathrm{r}=\text { jari-jari talang }(\mathrm{D} / 2) \text { (m atau inci) } \\
& \mathrm{t}=\begin{array}{l}
\text { ukuran panjang talang yang } \\
\text { digunakan }(\mathrm{m})
\end{array}
\end{aligned}
$$

\section{Perencanaan Turbin}

Setelah perhitungan pipa penstock telah didapat maka dapat diketahui ketinggian efektif air. Untuk perencanaan selanjutnya yaitu turbin dan generator dimana turbin yang digunakan adalah turbin propeller tipe open flume TC 60, dengan head minimumnya $3 \mathrm{~m}$. Putaran spesifik turbin yaitu $\pm 2700 \mathrm{rpm}$ (Linsley, 1995).

Perhitungan daya air (P) yang mengalir pada tubin dapat dihitung menggunakan persamaan (5):

$$
\mathrm{P}=\rho \times g \times Q \times \Delta h
$$

Dimana :

$$
\begin{aligned}
& \rho=\text { Massa jenis air }=1000 \mathrm{~kg} / \mathrm{m}^{3} \\
& \mathrm{~g}=\text { Grafitasi }=9,8 \mathrm{~m}^{2} / \mathrm{s} \\
& \mathrm{Q}=\text { Debit air } \\
& \Delta h=\text { Head }
\end{aligned}
$$

Daya turbin yang dihasilkan pada perencanaan ini dapat dihitung menggunakan persamaan (6):

$$
\mathrm{P}_{\text {turbin }}=\rho \times g \times Q \times \Delta h \times \eta_{t}
$$

Dimana:

$$
\begin{aligned}
& \mathrm{P}_{\text {turbin }}=\text { daya turbin (watt) } \\
& \eta_{t} \quad=\text { Efisiensi turbin }
\end{aligned}
$$

Pada perencanaan ini turbin yang akan dipakai adalah turbin Francis dan ada beberapa kemungkinan tipe turbin francis yang memiliki efisiensi yang berbeda - beda. Daya listrik yang dihasilkan turbin dapat dihitung menggunakan persamaan (7):

$$
P_{\text {listrik }}=P_{\text {air }} \times \eta_{g} \times \eta_{t}
$$

Dimana :

$$
\begin{aligned}
& P_{\text {air }}=\text { Daya air }(\text { watt }) \\
& \eta_{g}=\text { Efisiensi generator }=0,9 \\
& \eta_{t}=\text { Efisiensi turbin }=0,85
\end{aligned}
$$

\section{Perencanaan Generator}

Prinsip dasar generator adalah perubahan fluks magnetik yang melalui suatu kumparan penghantar menginduksikan arus listrik dalam kumparan sehingga dapat membangkikan daya yang besar. Output generator ditunjukkan dengan $\mathrm{kVA}$ dihitung menggunakan persamaan (8):

$$
S_{g}(V A)=\frac{(\rho \times 9,8 \times H \times Q \times \eta)}{P_{f}}
$$

Dimana :

$$
\mathrm{S}_{\mathrm{g}}=\text { Output dibutuhkan }(\mathrm{kVA})
$$

$\rho=$ Massa jenis air

$\mathrm{H}=$ Head efektif $(\mathrm{m})$

$\mathrm{Q}=\operatorname{Debit}\left(\mathrm{m}^{3} / \mathrm{s}\right)$

$\eta=$ Digabungkan efisiensi dari turbin dan generator.

$\mathrm{P}_{\mathrm{f}} \quad$ = Faktor daya.

Nilai kecepatan putaran dispesifikasikan menurut frekuensi (50 $\mathrm{Hz}$ ) dari jaringan listrik dan jumlah batang dapat ditentukan menggunakan persamaan (9) dan persamaan (10) berikut:

a. Untuk generator synchronous

$$
p=\frac{120 \times f}{N_{0}(r p m)}
$$

Dimana :

$$
\begin{aligned}
& \mathrm{p}=\text { Jumlah kutub } \\
& \mathrm{N}_{0}=\text { Nilai kecepatan putaran }(\mathrm{rpm}) \\
& \mathrm{f}=\text { Frekuensi jaringan }(\mathrm{hz}), \text { standar } \\
& \text { Indonesia } 50 \mathrm{~Hz}
\end{aligned}
$$

b. Untuk generator induksi

Kecepatan sedikit lebih tinggi dari pada generator synchrounous untuk excitasi dengan slip.

$$
\boldsymbol{N}(\boldsymbol{r p m})=(\mathbf{1}-\mathrm{S}) \times \boldsymbol{N}_{\mathbf{0}}
$$

Dimana :

$\mathrm{N}=$ Kecepatan actual dari generator induksi

$\mathrm{S}=$ Slip (secara normal $\mathrm{S}=0,02$ )

$\mathrm{N}_{0}=$ Nilai kecepatan putaran.

Sebagaimana kecepatan putaran ditetapkan dengan kecepatan dan jumlah batang generator. Frekwensi di Indonesia adalah $50 \mathrm{~Hz}$, kecepatan akan dipilih dari $1500 \mathrm{rpm}(50 \mathrm{~Hz})$.

\section{HASIL DAN PEMBAHASAN}

Data curah hujan yang diperoleh dari BMKG kota Padang

Data curah hujan yang digunakan yaitu data curah hujan periode Januari- 
Desember 2016 yang disajikan pada Tabel 1. berupa data dari rata-rata curah hujan kota padang Januari-Desember tahun 2016.

Berdasarkan Tabel 1. dapat dilihat rekapitulasi dari curah hujan Januari Desembar 2016. Dimana data yang didapat dari BMKG barupa hasil dari penjumlahan rata-rata hujan perhari yang dihitung dalam satu bulan. Kemudian jumlah bulanan tersebut dijumlahkan dan dibagi dengan jumlah hari terjadinya hujan. Sehingga rata-rata curah hujan yang diperoleh adalah $24.154 \mathrm{~mm} / \mathrm{m}^{2} / \mathrm{jam}$.

Tabel 1. Rata-Rata Curah Hujan Kota Padang Periode Januari-Desember 2016

\begin{tabular}{ccc}
\hline Bulan & $\begin{array}{c}\text { Curah Hujan } \\
\left(\mathbf{m m} / \mathbf{m}^{2} / \mathbf{j a m}\right)\end{array}$ & $\begin{array}{c}\text { Rata-Rata } \\
\left(\mathbf{m m} / \mathbf{m}^{2} / \mathbf{j a m}\right)\end{array}$ \\
\hline Januari & 207.7 & 11.539 \\
Februari & 358 & 27.538 \\
Maret & 648.2 & 36.011 \\
April & 417.5 & 26.094 \\
Mei & 476.5 & 23.825 \\
Juni & 627.2 & 44.800 \\
Juli & 144.4 & 9.627 \\
Agustus & 372.2 & 23.263 \\
September & 385 & 18.333 \\
Oktober & 602.2 & 33.456 \\
November & 299.6 & 14.267 \\
Desembar & 442.9 & 21.090 \\
\hline & Total per hari & 24.154 \\
& $\left(\mathbf{m m} / \mathbf{m}^{2} / \mathbf{j a m}\right)$ & \\
\hline
\end{tabular}

\section{Pengukuran luas atap bangunan}

Dalam perencanaan ini perhitungan dilakukan dari komponen awal, yaitu atap rumah dari rumah yang berukuran $12 \mathrm{~m} \mathrm{x}$ $8 \mathrm{~m}$ x $10 \mathrm{~m}$. Untuk perhitungan lebar atap rumah dimana dari tiap sisi kanan memiliki ukuran lebih panjang $1 \mathrm{~m}$ dari dinding bangunan dan kiri memiliki ukuran lebih panjang, yaitu $70 \mathrm{~cm}$. Ukuran atap bangunan dapat dilihat pada Gambar 5.

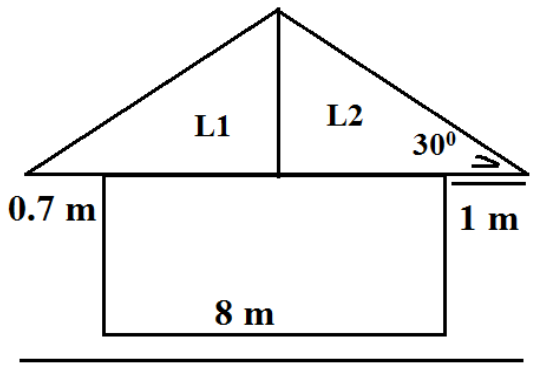

$9.7 \mathrm{~m}$

Gambar 5. Ukuran Lebar Atap Bangunan

Perhitungan lebar atap rumah dapat lakukan dengan menggunakan persamaan (1), diperoleh nilai $11,2 \mathrm{~m}$. Untuk perhitungan panjang atap rumah, dimana pada sisi depan dan belakang rumah memiliki ukuran yang lebih panjang dari dari panjang rumah yang diukur dari jarak dinding rumah ke ujung atap rumah. Ukuran panjang atap memiliki ukuran 85 cm lebih panjang dari pada panjang bangunan rumah, sehingga ukuran atap rumah menjadi $12 \mathrm{~m}+0.85 \mathrm{~m}+0.85 \mathrm{~m}=$ $13.7 \mathrm{~m}$.

Untuk menentukan luas atap bangunan dituliskan seperti pada persamaan (11) berikut:

$$
\begin{aligned}
L_{\text {atap }} & =p \quad x \quad l \\
L_{\text {atap }} & =p \quad x \quad l \\
& =13.7 \mathrm{~m} \times 11.2 \mathrm{~m} \\
& =153.44 \mathrm{~m}^{2}
\end{aligned}
$$

Tinggi yang dimiliki oleh rumah dari atap rumah hingga puncak atau bagian atap tertinggi memiliki tinggi $10 \mathrm{~m}$. Sedangkan untuk tinggi dari atap talang air ke dasar rumah yaitu $7 \mathrm{~m}$.

\section{Perhitungan Debit Air}

Debit air adalah banyaknya air hujan yang ditampung pada bak penampung(tangki). Sedangkan tinggi jatuh air adalah ketinggian bangunan rumah. Penentuan debit air hujan didapatkan dari data yang diperoleh dari BMKG. 
a. Curah hujan rata-rata periode JanuariDesember 2016.

Curah hujan berkisar $24.154 \mathrm{~mm} / \mathrm{m}^{2} /$ jam. Dimana dalam $1 \mathrm{~m}^{2}$ hujan yang turun $24.154 \mathrm{~mm}$ dalam 1 jam. Maka curah hujan yang didapatkan :

$0.024154 \mathrm{~m} \mathrm{x} 1 \mathrm{~m}^{2}=0.024154 \mathrm{~m}^{3}=$ 24.154 liter/jam $=24.154$ liter $/ 60$ menit $=0.403$ liter $/$ menit.

b. Debit air hujan pada luas permukaan atap rumah:

Untuk menghitung besarnya debit air yang ada pada permukaan rumah dapat menggunakan persamaan (12).

$Q_{\text {air hujan }}: L_{\text {atap }} x$ curah hujan

Maka untuk perhitungan dapat diperoleh:

$$
\begin{aligned}
D_{\text {air }} & =\text { luas atap x curah hujan } \\
& =153.44 \mathrm{~m}^{2} \times 0.403 \text { litar/menit } \\
& =61.836 \text { liter/menit }
\end{aligned}
$$

\section{Perencanaan Pipa Pesat}

Dalam perencanaan ini pipa yang digunakan sebagai pipa pesat yaitu pipa jenis PVC yang di jual dipasaran. Pipa yang memiliki diameter 1.5 inch. Bila jadikan pada satuan $\mathrm{cm}=3,75 \mathrm{~cm}$. Untuk menghitung luas penampang menggunakan persamaan (13):

$$
A=\pi r^{2}
$$

Maka untuk perhitungan dapat diperoleh:

$$
\begin{aligned}
& A=\pi r^{2} \\
& A=3,14 \times(1 / 2 \times 3,75 \mathrm{~cm})^{2} \\
& A=11,039 \mathrm{~cm}^{2} \\
& A=0.0011 \mathrm{~m}^{2}
\end{aligned}
$$

Untuk menghitung kecepatan aliran air yang keluar dari tangki dapat digunakan persamaan (14):

$$
v=\sqrt{2 g h}
$$

Maka untuk perhitungan dapat diperoleh untuk tangki 5100 liter dengan tinggi 2,1 $\mathrm{m}(210 \mathrm{~cm})$, maka $\mathrm{h}=2 \mathrm{~m}$

$$
\begin{aligned}
& v=\sqrt{2 g h} \\
& v=\sqrt{2 \times 9,8 \times 2} \\
& \mathrm{v}=6,26 \mathrm{~m} / \mathrm{s}
\end{aligned}
$$

Panjang pipa yang digunakan sepanjang tiga meter terhitung dari jarak lubang tangki ke tanah yaitu 3 meter.
Dapat dihitung dengan mengacu pada persamaan (2), sehingga dapat diperoleh:

$$
\begin{aligned}
& P=\sqrt{h^{2}+j^{2}} \\
& P=\sqrt{3^{2}+0,5^{2}} \\
& P=\sqrt{11,25} \\
& P=3,35 m
\end{aligned}
$$

Debit air yang digunakan untuk memutar turbin yaitu debit air yang tertampung pada tangki air. Untuk menghitung debit air dapat dihitung mengacu pada persamaan (3), sehingga diperoleh untuk tangki air 5100 liter:

$$
\begin{aligned}
& Q=A . V \\
& \mathrm{Q}=0.0011 \mathrm{~m}^{2} \times 6,26 \mathrm{~m} / \mathrm{s} \\
& \mathrm{Q}=0,0069 \mathrm{~m}^{3} / \mathrm{s} \\
& \mathrm{Q}=6.9 \text { liter } / \mathrm{s}
\end{aligned}
$$

Berdasarkan Tabel 2. dapat dilihat akumulasi berdasarkan volume tangki air. Hasil yang diperoleh dari lama waktu pengisian tangki air yang direncanakan oleh debit air dari atap rumah, yaitu sebesar 61.836 liter/menit. Dimana volume tangki air berpengaruh terhadap lama waktu pengisian tangki. Semakin besar tangki yang digunakan maka weaktu pengisian air akan semakin lama dan sebaliknya, semakin kecil volume tangki maka waktu pengisian semakin cepat.

Tabel 2. Akumulasi volume, waktu pengisian, kecepatan, debit air

\begin{tabular}{ccccc}
\hline $\begin{array}{c}\text { Volum } \\
\mathbf{e} \\
\text { tangki } \\
\mathbf{a i r} \\
\text { (liter) }\end{array}$ & $\begin{array}{c}\text { Tingg } \\
\mathbf{i} \\
\text { tangk } \\
\mathbf{i}(\mathbf{m})\end{array}$ & $\begin{array}{c}\text { Waktu } \\
\text { Pengisia } \\
\mathbf{n} \\
(\mathbf{m e n i t})\end{array}$ & $\begin{array}{c}\text { Kecepata } \\
\mathbf{n}(\mathbf{m} / \mathbf{s})\end{array}$ & $\begin{array}{c}\text { Debi } \\
\mathbf{t} \text { Air } \\
(\mathbf{I} / \mathbf{s})\end{array}$ \\
\hline 4100 & 2 & 66.304 & 6.26 & 6.9 \\
\hline 5100 & 2 & 82.476 & 6.26 & 6.9 \\
\hline 8000 & 2.3 & 129.37 & 6.7 & 7.4 \\
\hline 11000 & 3.3 & 177.89 & 8.04 & 8.8 \\
\hline 16000 & 2.9 & 258.75 & 7.54 & 8.3 \\
\hline
\end{tabular}

\section{Perencanaan turbin}

Jenis turbin turbin yang digunakan yaitu turbin propeller tipe open flume TC 60. Putaran spesifik turbin yaitu \pm 2700 rpm. 
Daya air yang dihasilkan turbin diperoleh dengan mengacu kepada persamaan (5), sehingga diperoleh nilai daya air $\left(\mathrm{P}_{\text {air }}\right)$ sebesar 202,86 Watt. Daya turbin yang dihasilkan pada perencanaan ini dapat dihitung dengan mengacu pada persamaan (6), diperoleh sebesar 173,43 Watt. Daya listrik dihitung mengacu kepada persamaan (7) , yaitu sebesar 155,19 Watt.

Berdasarkan hasil perhitungan dengan menggunakan turbin propeller tipe open flume TC 60, debit air yang digunakan berdasarkan debit air dari desain turbin tersebut yaitu sebesar 5,5 liter/s. Dimana pada perencanaan ini tinggi ( head) diatur berdasarka head maksimum dari desain turbin yaitu $3 \mathrm{~m}$. Sehingga daya keluaran turbin akan dipengaruhi oleh debit dan head. semakin besar debit dan semakin tinggi head daya yang dihasilkan akan sekain besar. Namun dalam keadaan ini head hanya diatur pada ketinggian $3 \mathrm{~m}$ agar kerja turbin lebih optimal. Jika head rendah maka turbin akan bekerja kurang optimal.

\section{Perencanaan Generator}

Output generator yang direncanakan ditunjukkan dengan VA yang dihitung mengacu pada persamaan (8), dengan nilai sebesar 194,875 VA.

Nilai kecepatan putaran dispesifikasikan menurut frekuensi (50 $\mathrm{Hz}$ ) dari jaringan listrik dan jumlah batang mengacu pada persamaan (9) dan (10) berikut :

a. Untuk generator synchronous

$$
P=\frac{120 \times f}{N_{0}(r p m)}
$$

Maka diperoleh:

$$
P=\frac{120 \times f}{N_{0}(r p m)}=\frac{120 \times 90}{2700}=4 \text { Nos }
$$

b. Untuk generator induksi

Kecepatan sedikit lebih tinggi dari pada generator synchrounous untuk excitasi dengan slip. Mengacu kepada rumus (10).
$N(r p m)=(1-S) \times N_{0}$

(10)

Maka : $N(r p m)=(1-S) \times N_{0}$

$N(\mathrm{rpm})=(1-0,02) \times 2700$ $=0,98 \times 2700=2646 \mathrm{rpm}$

Dari hasil perhitungan generator daya yang diperkirakan 154.63 VA dan daya yang didapatkan berdasarkan listrik yang dihasilkan dari putaran turbin sama dan terpenuhi. Generator yang digunakan disini merupakan generator magnet permanen yaitu generator syncron 1 fasa. Perhitungan banyak kutub yang dilakukan berdasarkan dengan rumus matematis sama dengan jumlah kutub pada desain generator. Karena generator seporos dengan turbin maka putaran generator akan sama dengan putaran turbin yaitu \pm $2700 \mathrm{rpm}$.

\section{KESIMPULAN}

Berdasarkan hasil perhitungan dan pembahasan yang telah dilakukan untuk rencana Pembangkit Listrik Tenaga Picohydro (PLTPh) dapat disimpulkan sebagai berikut:

1. Debit air hujan yang didapat dari luas permukaan atap adalah 61.836 liter/menit. Volume tangki air yang digunakan untuk menampung air adalah 5100 liter. Sedangkan debit air yang dapat dimanfaatkan untuk memutar turbin adalah 6.9 liter/s yang dialiri oleh pipa berukuran $1.5 \mathrm{inch}$.

2. Jenis turbin yang digunakan pada perencanaan ini adalah turbin propeller tipe open flume TC 60 yang seporos dengan generator sinkron 1 fasa dengan kecepatan $2700 \mathrm{rpm}$.

3. Dari hasil perhitungan yang dilakukan terhadap daya, maka daya air yang tersedia 202,86 watt, daya turbin yang dihasilkan 173,43 $\mathrm{W}$, dan daya listrik yang dihasilkan adalah 123,7 watt. Dengan efisiensi pada turbin 0,85 .

4. Dari perhitungan dari data, perencanaan output generator adalah 154.63 VA dan output yang didapatkan 
yaitu 155.19 watt. Putaran pada generator akan sama dengan putaran turbin karena genetaror dipasang seporos dengan turbin. dan generator dapat menghasilkan lebih dari 100 watt.

5. Perkiraan biaya untuk pembangunan Pembangkit Listrik Tenaga Pichydro ini \pm Rp. 12.713.855.

\section{DAFTAR PUSTAKA}

A. Sugianto,"Studi Perencanaan Pembangkit Listrik Picohydro (PLTPh) Untuk Produksi Keripik di Daerah Banjarnegara". Jurnal Teknik Elektro Universitas Gajah Mada, 2012.

A. Arismunandar, "Teknik Tegangan Tenaga Listrik, Jilid I Pembangkitan Dengan Tenaga Air". Jakarta: PT. Pradya Paramita, 2000.

D. Shantika, "Perancangan Prototipe Piko Hydro PORTABLE 200 Watt," Semin. Nas. XII Rekayasa dan Apl. Tek. Mesin di Ind. Kampus ITENAS Bandung, 17-18 Desember 2013, 2013.

J. Febryan, "Perencanaan Pembangkit Listrik Tenaga Air Skala Pikohidro di Area Wisata Curug Embun Desa Pematang Bange Kota Pagaralam", Skripsi Jurusan Teknik Elektro Fakultas Teknik Universitas Sriwijaya, 2018.

K. Linsley, Yoseph B. Franzini, "Tekhnik Sumber Daya Air. Jilid I". (Alih bahasa Ir. Djoko Sasongko, M.Sc). Jakarta: Erlangga, 1995.

Ranald V. Giles, "Mekanika Fluida dan Hidrolika". (Alih bahasa Ir. Herman Widodo Soemitro), Jakarta: Erlangga, 1984.

Risnandar, Finsa Anugrah Pratama, and
Novrinaldi, "Gis untuk menentukan potensi pembangkit Piko-Hidro," vol. 1, November 2011.

Sujadi, "Metodologi Penilitian Pendidikan," Jakarta, 2002.

W. Budiman and N. Hariyanto, "Perancangan dan Realisasi Sistem Pengisian Baterai 12 Volt 45 Ah pada Pembangkit Listrik Tenaga Pikohidro di UPI Bandung," J. Reka Elkomika, vol. 2, no. 1, pp. 1-12, 2014. 